\title{
Expression of Efflux Pump Activity in Multidrug Resistant (MDR) E. coli isolates by Cartwheel Method
}

\author{
Thakur Datt ${ }^{1 *}$, Shyama Datt $^{1}$, Iqbal Singh ${ }^{2}$, Simrita Singh $^{3}$ and N. P. Singh ${ }^{1^{*}}$ \\ ${ }^{1}$ Department of Microbiology, ${ }^{2}$ Department of Surgery, University College of Medical \\ Sciences and Guru Teg Bahadur Hospital, Delhi -110095, India \\ ${ }^{3}$ NCDC, 22-Shamnath Marg, Delhi-110054, India \\ *Corresponding author
}

\section{A B S T R A C T}

\section{Keywords}

Optical density,

Antibiotic

resistance,

Phenotypes,

Permeability,

Bacteria

\section{Article Info}

Accepted:

12 November 2019

Available Online:

10 December 2019
Bacteria resist antibiotic action through several mechanisms, including target al., teration, drug inactivation, decreased permeability, and increased efflux. The aim of the study is detection of EP mediated MDR phenotypes in E. coli by using EB agar Cartwheel method. The agar-based method is used to evaluate as many as twelve bacterial strains per plate and has been termed the EB-agar cartwheel method. E. coli strains were grown in $5 \mathrm{ml}$ peptone water until they reached an optical density (OD) 0.6 at $600 \mathrm{~nm}$, then OD of the cultures was adjusted to 0.5 of a McFarland standard. EB concentrations starting from $0,0.5,1,1.5,2 \& 2.5 \mathrm{mg} / 1$ were prepared in distilled water on the same day of the experiment from stock solution $\left(50 \mathrm{mg} / \mathrm{ml}\right.$, stored at $\left.4^{\circ} \mathrm{C}\right)$ and protected from light. The evaluation of efflux-pump activity was done on70 MDR E. coli strains isolated from urine specimens of clinically suspected UTI patients of age 18- 80 years. The prevalence of active efflux was observed in 60\% (42/70) MDR E. coli strains. The high prevalence of an active efflux system in the present study in MDR $E$. coli isolates indicate that efflux activity-based antibiotic resistance is one of the mechanism of drug resistance prevalent in MDR E. coli isolates.

\section{Introduction}

Infections due to multidrug resistant (MDR) Gram-negative bacteria poses public health concern worldwide (Nikaido, 2009; Poole 2005) and infection due to MDR gram negative organism is one of the major cause of treatment failure due to reduced arsenal of antibiotic options. MDR is most commonly defined as resistance to $\geq 3$ classes of antibiotics (Falagas et al., 2006). Bacteria resist antibiotic action through various mechanisms, including target alteration, drug inactivation, decreased permeability, and 
increased efflux (Martins A 2013). Both Gram-negative and Gram-positive bacteria have efflux pumps (EPs), which is one of defense mechanism playing important role in the expression of MDR phenotype. EPs recognize and rapidly expel two or more structurally unrelated antibiotics and other harmful compounds that somehow manage to reach the periplasm of the bacteria, before coming in contact with their corresponding target sites (Poole, 2007; Piddock, 2006; Tikhonova et al., 2004; Nikaido, 2003; Nikaido, 1996). Efflux mediated resistance in Gram-negative bacteria is more complex due to the molecular architecture of the cell envelope (Kumar and Schweizer, 2005; Nikaido, 1998).

EPs are classified in two super families on the basis of their energy requirement. EP that derives their energy from the hydrolysis of ATP is part of the ATP binding cassette $(A B C)$ superfamily. These EP can be inhibited by agents that inhibit ATPases (kinases, phosphorylases, etc.). The other types of EP, the ones that derive their energy from the proton motive force, are not affected by agents that inhibit the EP of the ABC super family. Efflux systems that expel a broad range of chemically and structurally unrelated noxious compounds from the bacterium do so in an energy-dependent manner, without drug modification, contributing to the MDR phenotype of important bacterial pathogens (Kumar and Schweizer, 2005; Webber and Piddock, 2003; Tenover, 2006; Poole, 2007; Piddock, 2006; Li and Nikaido, 2004; Nikaido and Zgurskaya, 1999).

In the present study, we have demonstrated active efflux activity in bacterial isolates of clinical origin which involve the assessment of minimum fluorescence concentration of ethidium bromide (a common substrate to EP) in-side the bacterial cell. This is a simple method that uses Trypticase Soy agar plates containing increasing concentrations of EB (Martins et al., 2006) to detect several bacterial isolates inoculated as a spoke of wheel simultaneously for efflux activity. So the term EB-agar cartwheel method is being used.

\section{Materials and Methods}

\section{Samples}

This study was done in the Department of Microbiology on total of 70 non-repetitive urinary isolates of MDR E. coli, isolated from clinically suspected cases of UTI admitted in hospital or outpatient department of Guru Teg Bahadur Hospital, a tertiary care hospital in Delhi, India, between November 2017 and October 2019.

\section{Sample collection}

As instructed freshly voided, early midstream urine sample was collected from the patients directly into the sterile wide mouth screwcapped universal container. For each patient the collection date, age, sex, urine culture details were registered.

\section{Study population}

Urine samples with significant bacteriuria i.e. $\geq 10^{5} \mathrm{cfu} / \mathrm{ml}$ (Kass 1957) from patients of age $\geq 18$ to 80 years with at least one sign or symptom of UTI (dysuria, frequency, urgency, perineal pain, flank pain or costovertebral tenderness) were included in this study. The study was conducted after due approval from Institutional Ethics Committee-Human Research of UCMS and GTBH, Delhi.

\section{Urine culture}

samples were processed and cultured on Cystein Lactose Electrolyte Deficient (CLED) agar medium. The culture plates were 
incubated aerobically at $37^{\circ} \mathrm{C}$ for overnight and monomorphic yellow colonies with 3-4 $\mathrm{mm}$ diameter were looked out. The urine cultures were classified as negative when bacterial growth was lower than $10^{3} \mathrm{cfu} / \mathrm{ml}$.

\section{Identification of bacterial isolates}

Bacterial isolates were confirm as E. coli in the basis of colonial morphology, microscopy and by using a battery of biochemical tests (Collee et al., 2006).

Antimicrobial susceptibility test for MDR isolates and ESBL producer

The AST was performed according to modified Kirby-Bauer disk diffusion method (Bauer et al., 1996) and result was evaluated according to CLSI guidelines (CLSI M100 S27). An isolate was considered as multidrug resistant when it was resistant to $\geq 3$ groups of antibiotics (Magiorakos et al., 2011) and in present study an isolate was considered as MDR if found resistant to any of the third generation Cephalosporins, any of Carbapenemes and any other class of antibiotic.

\section{Reference strain}

ATCC E. coli 25922 served as negative reference strain in the present study.

\section{Evaluation of efflux activity}

E. coli strains were grown in $5 \mathrm{ml}$ peptone water until they reached an optical density (OD) 0.6 at $600 \mathrm{~nm}$. The OD of the cultures was adjusted to 0.5 of a McFarland standard. EB concentrations starting from $0,0.5,1,1.5$, 2 and $2.5 \mathrm{mg} / \mathrm{l}$ were prepared in distilled water on the same day of the experiment from stock solution $\left(50 \mathrm{mg} / \mathrm{ml}\right.$, stored at $\left.4^{\circ} \mathrm{C}\right)$ and protected from light. Tryptic soy agar (HiMedia Mumbai, India) plates containing varying EB concentrations were prepared on the same day of the experiment and protected from light. The plates were then divided into sectors by radial lines (cartwheel pattern).

A swab was dipped into each OD adjusted culture and reference strain and squeezed against the inside of the tube to remove excess volume and then swab was streaked on EBagar plates starting from the centre towards the periphery of the plates. The swabbed EBagar plates were then incubated at $37^{\circ} \mathrm{C}$ for overnight and examined under the UV transilluminator. The minimum concentration of EB that produced fluorescence of the bacterial mass was recorded (Martins et al., 2011) and compared with reference strain.

\section{Interpretation}

An isolate was considered as positive when it had fluorescence value above than the fluorescence value of reference strain i.e. above $0.5 \mathrm{mg} / \mathrm{l}$.

\section{Results and Discussion}

A total of 70 multi drug resistant E. coli strains isolated from clinically suspected UTI patients were included in this study for the evaluation of efflux-pump activity by EB agar Cartwheel method. The age distribution of the patients in the sample set was 18- 80 years (mean and standard deviation 43.01 \pm 17.72 years). From total 70 patients, $50(71.43 \%)$ were female, and 20 (28.57\%) male patients.

The EB-agar cartwheel method used for the presumptive evaluation of active efflux system showed active efflux activity in 42 strains (Fig. 1). Clinical isolates without efflux pump activity were found to fluoresce at $0.5 \mathrm{mg} / \mathrm{l}$ concentration of EB as observed in the ATCC E. coli 25922 strains taken as negative control. The minimum concentration of EB which showed fluorescence considered as active 
efflux activity was $1 \mathrm{mg} / \mathrm{l}$ (Fig. 2). The prevalence of active efflux was $60 \%$ (42/70) in MDR E. coli strains isolated from urine samples of UTI patients. Among the above 42 MDR E. coli isolates $26.19 \%$ (11/42) showed highly active efflux activity i.e. expressing fluorescence at a concentration $\geq 2.5 \mathrm{mg} / \mathrm{l}$. The highly active efflux activity was more prevalent in males $(41.67 \%)$ as compared to females (20\%) (Fig. 3 and Table 1).

Distribution of active efflux was more prevalent in $71-80$ age group $85.71 \%(6 / 7)$ followed by $21-30$ age group $72.22 \%$ (13/18) then 51-60 age group $71.42 \%$ (5/7) and highly active efflux activity was seen in 61-70 age group i.e. $66.67 \%$ (2/3) (Table 2). Among female patients high prevalence of active efflux system was seen in 21-30 age group $85.61 \%(11 / 13)$ followed by $31-40$ and 51-60 age group i.e. $78.57 \%(11 / 14)$ and $66.67 \%$ $(2 / 3)$, while in male patients all the isolates in 61-70 and 71-80 age groups were showing active EP system i.e. 2/2 (100\%), 5/5 (100\%) followed by 51-60 age group i.e. 75\% (3/4). Among $E$. coli isolates from female patients, highly active EP was seen only in two age groups 21-30 and 31-40 i.e.27.27\% (3/11) but in isolates of male patients it was seen in four age groups, however in 61-70 age group all the E. coli isolates were showing highly Active EP (2/2) (Table 3).

Majority of MDR E. coli $64.29 \%$ (45/70) isolates were from IPD patients and remaining $35.71 \%(25 / 70)$ isolates were from OPD patients (Table 2).

Among isolates of $E$. coli from IPD cases $53.55 \%(25 / 45)$ isolates of $E$. coli showed active efflux and $24 \%(6 / 25)$ were having highly active EP. The active EP $77.78 \%$ (7/9) were seen in 31-40 age group followed by 21 30 age group $72.73 \%$ (8/11) and highly active EP was seen in 51-60 age group $40 \%(2 / 5)$ followed by $31-40$ age group $28.57 \%(2 / 7)$ and then 21-30 age group 25\% (2/8) (Table 2).

Isolates of female UTI patients admitted in IPD were $77.78 \%(35 / 45)$ and remaining isolates $22.22 \%(10 / 45)$ were from male UTI patients. E. coli isolates with active efflux system was higher in females i.e. $57.14 \%$ (20/35) as compared to males $40 \%$ (4/10). A significantly high prevalence of highly active efflux system was observed in males i.e. $50 \%$ (2/4) as compared to females $20 \% \quad(4 / 20)$ (Table 1).

E. coli isolates in female patients in 31-40 age group showed $88.89 \%(8 / 9)$ active EP activity followed by isolates from 21-30 age group $80 \%(8 / 10)$ while in male patients it was observed in $75 \%$ (3/4) of the isolates from 5160 age group. Highly active EP activity was seen in isolates of 21-30 and 31-40 age groups in female i.e. $25 \%(2 / 8)$ each in both the groups and in isolates of $E$. coli from the male patients all the isolates were showing highly active EP activity i.e. 100\% (1/1) in 71-80 age group followed by $66.67 \%(2 / 3)$ in $51-60$ age group (Table 4).

Among E. coli isolates of OPD cases active EPs activity were seen in 68\% (17/25). Among these 17 isolates highly active EP was $31.25 \%(5 / 16)$. Interestingly all the isolates in $61-70(2 / 2)$ and 71-80 (4/4) age groups were having active EP activity followed by $21-30$ and $18-20$ age groups i.e. $71.43 \%(5 / 7)$ and $66.67 \%(2 / 3)$ respectively. Similarly in $61-70$ age group all (2/2) the isolates of $E$. coli were showing $100 \%$ highly active EP activity (Table 2).

Among isolates of $E$. coli from OPD patients, the high active EP activity was seen approximately equal in male patients $70 \%$ (7/10) as compared to female patients $66.67 \%$ $(10 / 15)$. 
Table.1 Distribution of Male and Female active and highly active EP percentage in MDR E. coli isolates in Ward and OPD cases

\begin{tabular}{|c|c|c|c|c|}
\hline \multirow[t]{2}{*}{ Sex } & \multicolumn{2}{|c|}{ Male } & \multicolumn{2}{|c|}{ Female } \\
\hline & OPD & Ward & OPD & Ward \\
\hline No. of isolates & $10(40 \%)$ & $\begin{array}{c}10 \\
(22.22 \%)\end{array}$ & $15(60 \%)$ & $\begin{array}{c}35(77.78 \\
\%)\end{array}$ \\
\hline Active Efflux & $7(70 \%)$ & $5(50 \%)$ & $\begin{array}{c}10 \\
(66.67 \%)\end{array}$ & $\begin{array}{c}20 \\
(57.14 \%)\end{array}$ \\
\hline $\begin{array}{l}\text { Highly Efflux } \\
\text { Activity ( } \geq 2.5)\end{array}$ & $\begin{array}{c}3 \\
(42.86 \%)\end{array}$ & $2(40 \%)$ & $2(20 \%)$ & $4(20 \%)$ \\
\hline
\end{tabular}

Table.2 Age group wise distribution of Total Ward and OPD isolates

\begin{tabular}{|c|c|c|c|c|c|c|c|c|c|}
\hline \multirow[t]{2}{*}{ Age } & \multicolumn{3}{|c|}{ Total isolates } & \multicolumn{3}{|c|}{ Ward } & \multicolumn{3}{|c|}{ OPD } \\
\hline & Total & $\begin{array}{l}\text { Active } \\
\text { Efflux }\end{array}$ & $\begin{array}{l}\text { Highly } \\
\text { active } \\
\text { Efflux } \\
\text { activity } \\
(\geq 2.5)\end{array}$ & Total & $\begin{array}{l}\text { Active } \\
\text { Efflux }\end{array}$ & $\begin{array}{l}\text { Highly } \\
\text { active } \\
\text { Efflux } \\
\text { activity } \\
(\geq 2.5)\end{array}$ & Total & $\begin{array}{l}\text { Active } \\
\text { Efflux }\end{array}$ & $\begin{array}{l}\text { Highly } \\
\text { active } \\
\text { Efflux } \\
\text { activity } \\
(\geq 2.5)\end{array}$ \\
\hline $18-20$ & 5 & $2(40 \%)$ & 0 & 2 & 0 & 0 & 3 & $\begin{array}{c}2 \\
(66.67 \%)\end{array}$ & 0 \\
\hline 21-30 & 18 & $\begin{array}{c}13 \\
(72.22 \%)\end{array}$ & $3(23.1 \%)$ & 11 & $\begin{array}{c}8 \\
(72.73 \%)\end{array}$ & $2(25 \%)$ & 7 & $\begin{array}{c}5 \\
(71.43 \%)\end{array}$ & $1(20 \%)$ \\
\hline $31-40$ & 16 & $\begin{array}{c}11 \\
(68.75 \%)\end{array}$ & $3(23.1 \%))$ & 9 & $\begin{array}{c}7 \\
(77.78 \%)\end{array}$ & $2(28.57 \%)$ & 7 & $\begin{array}{c}4 \\
(57.14 \%)\end{array}$ & $1(25 \%)$ \\
\hline $41-50$ & 0 & $2(20 \%)$ & 0 & 8 & $2(25 \%)$ & 0 & 2 & 0 & 0 \\
\hline $51-60$ & 7 & $\begin{array}{c}5 \\
(71.42 \%)\end{array}$ & $2(40 \%)$ & 7 & $\begin{array}{c}5 \\
(28.57 \%)\end{array}$ & $2(40 \%)$ & $\mathbf{0}$ & 0 & 0 \\
\hline 61-70 & 7 & $\begin{array}{c}3 \\
(42.86 \%)\end{array}$ & $2(66.67 \%)$ & 5 & $1(20 \%)$ & 0 & 2 & $2(100 \%)$ & $2(100 \%)$ \\
\hline $71-80$ & 7 & $\begin{array}{c}6 \\
(85.71 \%)\end{array}$ & $1(16.67 \%)$ & 3 & $\begin{array}{c}2 \\
(66.67 \%)\end{array}$ & 0 & 4 & $4(100 \%)$ & $1(25 \%)$ \\
\hline total & 70 & $42(60 \%)$ & $11(26.19 \%)$ & 45 & $\begin{array}{c}25 \\
(53.55 \%)\end{array}$ & $6(24 \%)$ & 25 & 17 (68\%) & $\begin{array}{c}5 \\
(31.25 \%)\end{array}$ \\
\hline
\end{tabular}


Table.3 Age group wise distribution of female and male isolates

\begin{tabular}{|c|c|c|c|c|c|c|}
\hline \multirow{2}{*}{$\begin{array}{c}\text { Age } \\
\text { Group }\end{array}$} & \multicolumn{3}{|c|}{ No. of Female isolates } & \multicolumn{3}{c|}{ No. of Male isolates } \\
\cline { 2 - 7 } & Total & $\begin{array}{c}\text { Active } \\
\text { Efflux }\end{array}$ & $\begin{array}{c}\text { Highly active } \\
\text { Efflux activity } \\
(\geq \mathbf{2 . 5})\end{array}$ & Total & $\begin{array}{c}\text { Active } \\
\text { Efflux }\end{array}$ & $\begin{array}{c}\text { Highly active } \\
\text { Efflux activity } \\
(\geq 2.5)\end{array}$ \\
\hline $\mathbf{1 8 - 2 0}$ & $\mathbf{5}$ & $2(40 \%)$ & 0 & $\mathbf{0}$ & 0 & 0 \\
\hline $\mathbf{2 1 - 3 0}$ & $\mathbf{1 3}$ & $11(85.61 \%)$ & $3(27.27 \%)$ & $\mathbf{5}$ & $2(40 \%)$ & 0 \\
\hline $\mathbf{3 1 - 4 0}$ & $\mathbf{1 4}$ & $11(78.57 \%)$ & $3(27.27 \%)$ & $\mathbf{2}$ & 0 & 0 \\
\hline $\mathbf{4 1 - 5 0}$ & $\mathbf{8}$ & $2(25 \%)$ & 0 & $\mathbf{2}$ & 0 & 0 \\
\hline $\mathbf{5 1 - 6 0}$ & $\mathbf{3}$ & $2(66.67 \%)$ & 0 & $\mathbf{4}$ & $3(75 \%)$ & $2(66.67 \%)$ \\
\hline $\mathbf{6 1 - 7 0}$ & $\mathbf{5}$ & $1(20 \%)$ & 0 & $\mathbf{2}$ & $2(100 \%)$ & $2(100 \%)$ \\
\hline $\mathbf{7 1 - 8 0}$ & $\mathbf{2}$ & $1(50 \%)$ & 0 & $\mathbf{5}$ & $5(100 \%)$ & $1(20 \%)$ \\
\hline Total & $\mathbf{5 0}$ & $30(60 \%)$ & $6(20 \%)$ & $\mathbf{2 0}$ & $12(60 \%)$ & $5(41.67 \%)$ \\
\hline
\end{tabular}

Table.4 Age group wise distribution of female and male isolates in ward cases

\begin{tabular}{|c|c|c|c|c|c|c|}
\hline \multirow{2}{*}{$\begin{array}{c}\text { Age } \\
\text { Group }\end{array}$} & \multicolumn{4}{|c|}{ Female } & \multicolumn{3}{c|}{ Male } \\
\cline { 2 - 7 } & Total & $\begin{array}{c}\text { Active } \\
\text { Efflux }\end{array}$ & $\begin{array}{c}\text { Highly active } \\
\text { Efflux activity } \\
(\geq 2.5)\end{array}$ & Total & $\begin{array}{c}\text { Active } \\
\text { Efflux }\end{array}$ & $\begin{array}{c}\text { Highly active } \\
\text { Efflux activity } \\
(\geq 2.5)\end{array}$ \\
\hline $\mathbf{1 8 - 2 0}$ & $\mathbf{2}$ & 0 & 0 & $\mathbf{0}$ & 0 & 0 \\
\hline $\mathbf{2 1 - 3 0}$ & $\mathbf{1 0}$ & $8(80 \%)$ & $2(25 \%)$ & $\mathbf{1}$ & 0 & 0 \\
\hline $\mathbf{3 1 - 4 0}$ & $\mathbf{9}$ & $8(88.89 \%)$ & $2(25 \%)$ & $\mathbf{1}$ & 0 & 0 \\
\hline $\mathbf{4 1 - 5 0}$ & $\mathbf{5}$ & $1(20 \%)$ & 0 & $\mathbf{2}$ & 0 & 0 \\
\hline $\mathbf{5 1 - 6 0}$ & $\mathbf{3}$ & $2(66.67 \%)$ & 0 & $\mathbf{4}$ & $3(75 \%)$ & $2(66.67 \%)$ \\
\hline $\mathbf{6 1 - 7 0}$ & $\mathbf{5}$ & $1(20 \%)$ & 0 & $\mathbf{0}$ & 0 & 0 \\
\hline $\mathbf{7 1 - 8 0}$ & $\mathbf{1}$ & 0 & 0 & $\mathbf{2}$ & $1(50 \%)$ & $1(100 \%)$ \\
\hline Total & $\mathbf{3 5}$ & $20(57.14 \%)$ & $4(20 \%)$ & $\mathbf{1 0}$ & $4(40 \%)$ & $3(75 \%)$ \\
\hline
\end{tabular}


Table.5 Age group wise distribution of female and male isolates in OPD cases

\begin{tabular}{|c|c|c|c|c|c|c|}
\hline \multirow{2}{*}{$\begin{array}{l}\text { Age } \\
\text { Group }\end{array}$} & \multicolumn{3}{|c|}{ Female } & \multicolumn{3}{|c|}{ Male } \\
\hline & Total & $\begin{array}{l}\text { Active } \\
\text { Efflux }\end{array}$ & $\begin{array}{l}\text { Highly active Efflux } \\
\text { activity }(\geq 2.5)\end{array}$ & Total & $\begin{array}{l}\text { Active } \\
\text { Efflux }\end{array}$ & $\begin{array}{l}\text { Highly active Efflux } \\
\text { activity }(\geq 2.5)\end{array}$ \\
\hline 18-20 & 3 & $2(66.67 \%)$ & 0 & $\mathbf{0}$ & 0 & 0 \\
\hline 21-30 & 3 & $3(100 \%)$ & $1(33.33 \%)$ & 4 & $2(50 \%)$ & 0 \\
\hline $31-40$ & 6 & $4(66.67 \%)$ & $1(25 \%)$ & 1 & 0 & 0 \\
\hline $41-50$ & 2 & 0 & 0 & $\mathbf{0}$ & 0 & 0 \\
\hline $51-60$ & $\mathbf{0}$ & 0 & 0 & $\mathbf{0}$ & 0 & 0 \\
\hline $61-70$ & $\mathbf{0}$ & 0 & 0 & 2 & $2(100 \%)$ & $2(100 \%)$ \\
\hline 71-80 & 1 & $1(100 \%)$ & 0 & 3 & $3(100 \%)$ & $1(33.33 \%)$ \\
\hline Total & 15 & $10(66.67 \%)$ & $2(20 \%)$ & 10 & $7(70 \%)$ & $3(42.86 \%)$ \\
\hline
\end{tabular}

Fig.1 Swabbed Cartwheel pattern of MDR E coli strains along with reference strain by the EBagar method. The reference strain fluoresce at $0.5 \mathrm{mg} / \mathrm{l}$ of EB concentration, whereas the active efflux strains fluoresce at higher EB concentrations, thus providing an EB concentration range within which these two levels of efflux was distinguished by this method
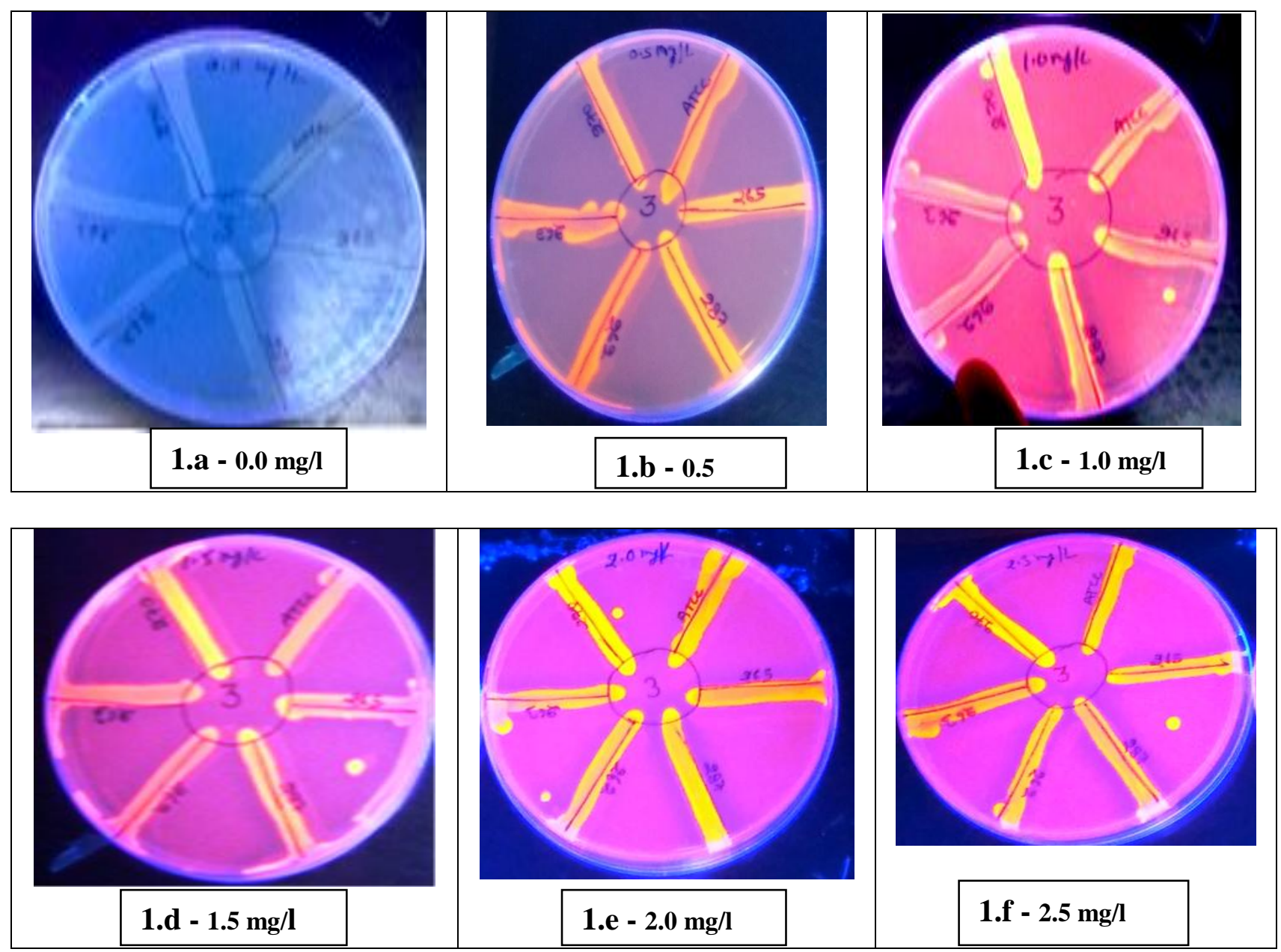
Fig.2 Distribution of MDR E. coli isolates in different EB concentration

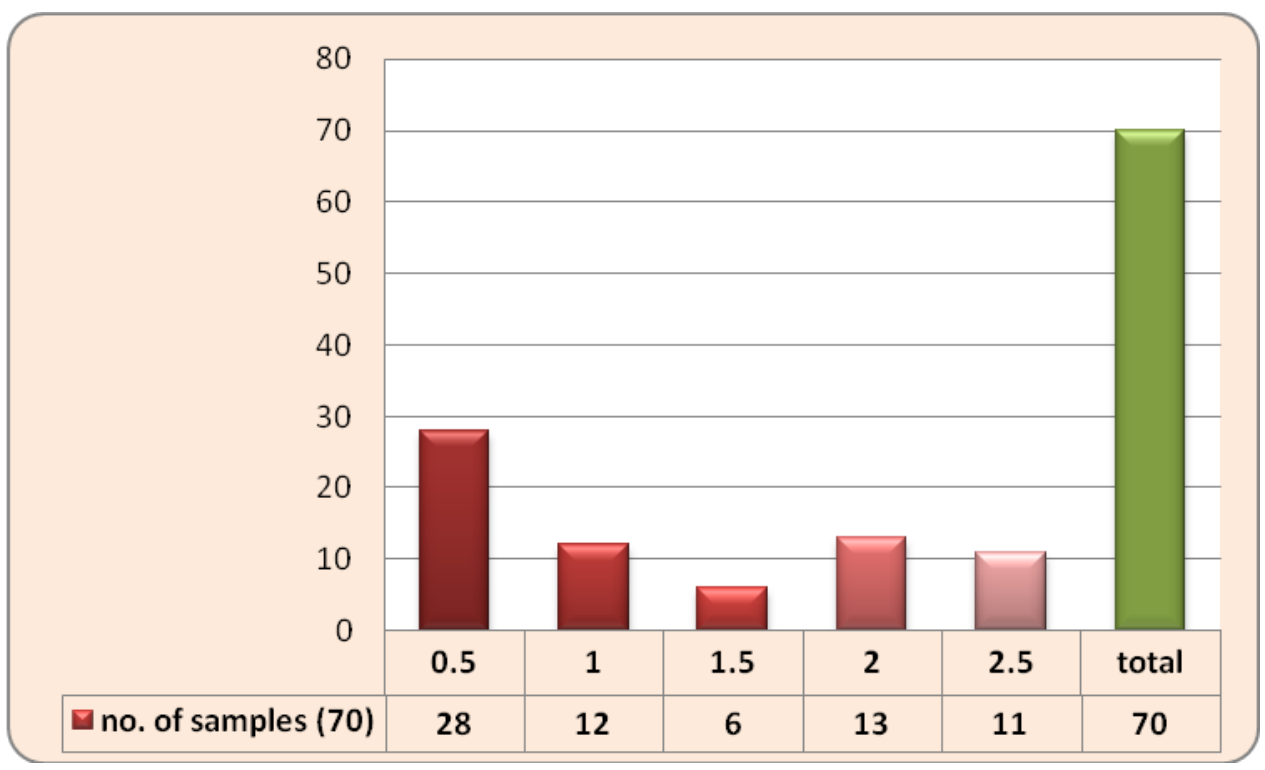

Fig.3 Distribution of Male and Female active and highly active EP in MDR E. coli isolates in Ward and OPD cases

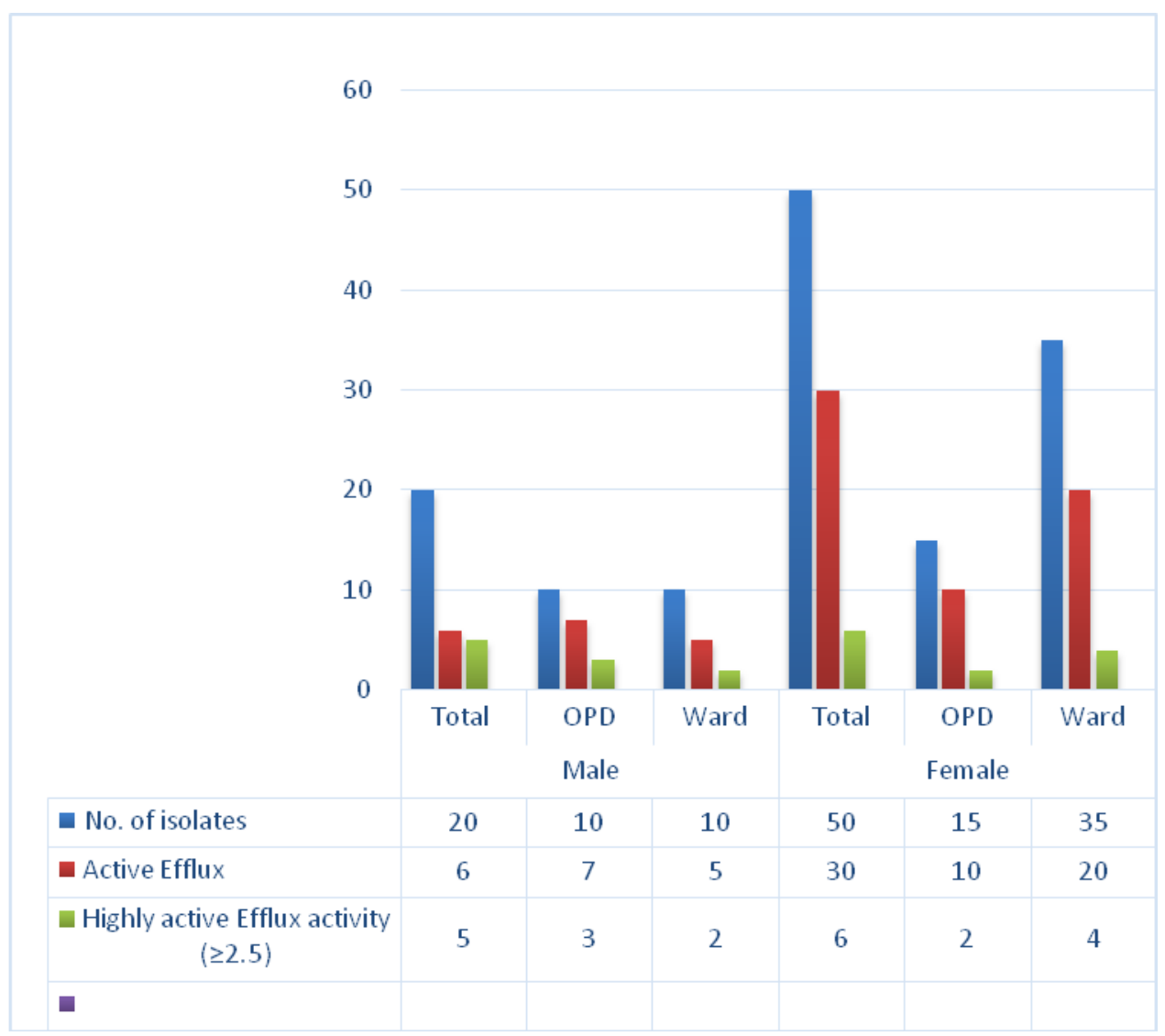


The overall prevalence of highly active EP system has been seen in male patients $42.86 \%$ $(3 / 7)$ as compared to female $20 \%(2 / 10)$ patients.

Interestingly all female patients of 21-30 and 71-80 age groups $(3 / 3,1 / 1)$ were showing active EP activity followed by 18-20, 31-40 age groups $66.67 \%(2 / 3,4 / 6)$ respectively. Among E. coli isolates the highly active EP system was seen only in two age groups of female patients i.e. 21-30 33.33 (1/3) followed by $31-40$ age group $25 \%$ (1/4). Among the male patients $100 \%$ active EP was seen in two age groups i.e. 61-70 and 71-80 age groups $(2 / 2,3 / 3)$ followed by $21-3050 \%$ (2/4). E. coli isolates of two age groups were showing highly active EP activity i.e. 61-70 and 71-80 among the OPD male patients. Among male patients of 61-70 age group, all E. coli isolates were showing highly active EP activity i.e. $100 \%(2 / 2)$ followed by $71-80$ age group $33.33 \%(1 / 3)$ (Table 5).

It is now documented that Efflux systems play a key role in the development of drug resistance in MDR Gram-negative bacteria that extrude two or more unrelated antibiotics prior to their reaching the intended targets (Poole 2007, Piddock 2006). Clinical laboratories should develop and implement new and improved methods for the timely identification of efflux mediated MDR phenotypes (Viveiros et al., 2008). The Cartwheel method employs EtBr as the pump substrate that allows the verification of the existence of an over expressed efflux system relative to the intrinsic efflux activities of the corresponding wild-type strain, which is used as a reference.

In our study ethidium bromide fluorescent test for active efflux activity was positive in $60 \%$ of the MDR E. coli isolates, while Suresh et $a l$. , reported $27.91 \%(12 / 43)$ efflux activity by ethidium bromide fluorescent test in MDR $E$. coli isolates, which is much lesser than the value of present study i.e. $60 \%$. However in their study the origin of clinical isolates is not detailed, moreover in addition to $E$. coli they have worked on Pseudomonas aeruginosa, Klebsiella spp. and Acinetobacter spp. also. Over all in their study EP activity was observed in $20 \%(25 / 123)$ of the total isolates (Suresh et al., 2016). In the present study the presence of active EP were equally distributed in male and female patients but the presence of highly active EP is significantly high in male patients $(41.67 \%$ ) as compared to female $(20 \%)$.

In this study the active EP was more prevalent in $E$. coli isolates from younger age group 2130 in female patients whereas in male patients it was commonly seen in patients of 61-80 age group. When cases were analyzed in between hospitalized and OPD patients, the active EP was more prevalent in OPD (64\%) cases as compared to ward $(53.55 \%)$ cases, however it not significant. In ward active EP was more prevalent in female but in OPD cases active EP was more in male patients. It is observed that highly active EP was more common in $E$. coli isolates from male cases in both ward and OPD patients. In the present study it is difficult to explain why EP activity was more common in isolates from OPD patients and why it was more common in isolates from male patients. This explanation may further require study on large number of isolates for conclusive findings.

The basis for the expression of multidrug resistance phenotype among clinical bacterial isolates has become a major concern since the therapy of the infections caused by these bacteria is problematic. The routine antimicrobial sensitivity tests fail to detect efflux pump mediated drug resistance. The high prevalence $(60 \%)$ of an active efflux system in the present study in MDR E. coli isolates indicate that efflux activity-based 
antibiotic resistance is more prevalent in MDR E. coli isolates. Hence, it is suggested that detection of active efflux pump must be included in the diagnostic regimen for providing a warning signal to the current therapy if continued as administered, may result in further escalation of resistance possibly including additional classes of antibiotics (Baquero, 2001) and implementation of accurate therapy to the patients. In targeting efflux, it is important to realize that efflux is only one of several available mechanisms of resistance in MDR bacteria to a given antimicrobial. Thus, its inhibition will have a significant therapeutic effect only for those antibiotics and in those organisms where efflux is the major contributor to resistance. The likelihood of false positives in such a screening cannot be ruled out as it has been reported that bacterial permeability to EB may also be highly decreased due to the down-regulation of porins (Martins, 2010).

\section{Lacunae}

Further molecular characterization may be done for the confirmation and evaluation of mechanisms of over expression in EP and down-regulation of porins.

The authors report no conflicts of interest.

\section{Acknowledgement}

This work was supported by National Centre for Disease Control, New Delhi.

\section{References}

Baquero F. Low-level antibacterial resistance: a gateway to clinical resistance. Drug Resistance Updates. 2001 Apr 1; 4(2): 93-105.

Bauer AW, Kirby WM, Sherris JC, Turck M. Antibiotic susceptibility testing by a standardized single disk method. Am J
Clin Pathol 1966; 45: 493- 6.

Clinical Laboratory Standards Institute (CLSI). Performance Standards for Antimicrobial Susceptibility Testing: Twentieth Informational Supplement. CLSI Document M100-S27.

Collee JG, Miles RS, Watt B. Tests for identification of bacteria. In: Collee JG, Fraser AG, Marmion BP, Simmons A., editors. Mackie and Mc Cartney Practical Medical Microbiology. 14th ed. Singapore: Churchill Livingstone; 2006. p. 131- 49.

Falagas ME, Koletsi PK, Bliziotis IA. The diversity of definitions of multidrugresistant (MDR) and pandrug-resistant (PDR) Acinetobacter baumannii and Pseudomonas aeruginosa. Journal of medical microbiology. 2006 Dec 1; 55(12): 1619-29.

Kass EH. Bacteriuria and the diagnosis of infections of the urinary tract; with observations on the use of methionine as a urinary antiseptic. AMA Arch Intern Med 1957; 100: 709- 14.

Kumar A, Schweizer HP. Bacterial resistance to antibiotics: active efflux and reduced uptake. Advanced drug delivery reviews. 2005 Jul 29; 57(10): 1486-513.

Li XZ, Nikaido H. Efflux-mediated drug resistance in bacteria. Drugs. 2004 Jan 1; 64(2): 159-204.

Magiorakos AP, Srinivasan A, Carey RB, Carmeli Y, Falagas ME, Giske CG, Harbarth S, Hindler JS, Kahlmeter G, Olsson-Liljequist B, et al.,: Multidrug resistant, extensively drug-resistant and pandrug-resistant bacteria: an international expert proposal for interim standard definitions for acquired resistance. Eur Soc Clin Microbiol Infect Dis 2011, 18: 268-281.

Martins A, Hunyadi A, Amaral L. Suppl 1: Mechanisms of Resistance in Bacteria: An Evolutionary Approach. The Open Microbiology Journal. 2013; 7: 53-8.

Martins M, Couto I, Viveiros M, Amaral L. Identification of efflux-mediated multidrug resistance in bacterial clinical 
isolates by two simple methods. In Antibiotic resistance protocols 2010 (pp. 143-157). Humana Press.

Martins M, Santos B, Martins A, Viveiros M, Couto I, Cruz A, PAGÈS JM, Molnar J, Fanning S, Amaral L. An instrumentfree method for the demonstration of efflux pump activity of bacteria. In vivo. 2006 Sep 1; 20(5): 657-64.

Martins M, Viveiros M, Couto I, Costa SS, Pacheco T, Fanning S, Pages JM, and Amaral L. Identification of efflux pumpmediated multidrug-resistant bacteria by the ethidium bromide-agar cartwheel method. in vivo. 2011 Mar 1; 25(2): 171-8.

Nikaido H, Zgurskaya HI. Antibiotic efflux mechanisms. Current opinion in infectious diseases. 1999 Dec 1; 12(6): 529-36.

Nikaido H. Molecular basis of bacterial outer membrane permeability revisited. Microbiol. Mol. Biol. Rev.. 2003 Dec 1; 67(4): 593-656.

Nikaido H. Multidrug efflux pumps of gramnegative bacteria. Journal of bacteriology. 1996 Oct; 178(20): 5853.

Nikaido $H$. Multidrug resistance in bacteria. Annual review of biochemistry. $2009 \mathrm{Jul}$ 7;78:119-46.

Nikaido $H$. The role of outer membrane and efflux pumps in the resistance of gramnegative bacteria. Can we improve drug access? Drug Resistance Updates. 1998 Jan 1; 1(2): 93-8.

Piddock LJ. Clinically relevant chromosomally encoded multidrug resistance efflux pumps in bacteria. Clinical microbiology reviews. 2006 Apr 1; 19(2): 382-402.

Poole K. Efflux pumps as antimicrobial resistance mechanisms. Annals of medicine. 2007 Jan 1; 39(3): 162-76.

Poole K. Efflux-mediated antimicrobial resistance. Journal of Antimicrobial Chemotherapy. 2005 Jul 1; 56(1): 20-51.

Suresh M, Nithy N, Jayasree P, Kumar P. Detection and prevalence of efflux pump-mediated drug resistance in clinical isolates of multidrug resistant Gram negative bacteria from north Kerala, India. Asi. J. Pharm. Clin. Res. 2016; 9: 324-7.

Tenover FC. Mechanisms of antimicrobial resistance in bacteria. The American journal of medicine. 2006 Jun 1; 119(6): S3-10.

Tikhonova EB, Zgurskaya HI. AcrA, AcrB, and TolC of Escherichia coli form a stable intermembrane multidrug efflux complex. Journal of Biological Chemistry. 2004 Jul 30; 279(31): 3211624

Viveiros M, Martins M, Couto I, Rodrigues L, Spengler G, Martins A, Kristiansen JE, Molnar J, and Amaral L. New methods for the identification of efflux mediated MDR bacteria, genetic assessment of regulators and efflux pump constituents, characterization of efflux systems and screening for inhibitors of efflux pumps. Current drug targets. 2008 Sep 1; 9(9): 760-78.

Webber MA, Piddock LJ. The importance of efflux pumps in bacterial antibiotic resistance. Journal of Antimicrobial Chemotherapy. 2003 Jan 1;51(1):9-11.

\section{How to cite this article:}

Thakur Datt, Shyama Datt, Iqbal Singh, Simrita Singh and Singh, N. P. 2019. Expression of Efflux Pump Activity in Multidrug Resistant (MDR) E. coli isolates by Cartwheel Method. Int.J.Curr.Microbiol.App.Sci. 8(12): 1325-1335. doi: https://doi.org/10.20546/ijcmas.2019.812.161 